\title{
Sustentabilidade da pesca na Amazônia
}

\author{
GERALDO MENDES DOS SANTOS \\ - ANA CAROLINA MENDES DOS SANTOS
}

\section{Histórico da pesca}

A

PESCA É UMA das atividades humanas mais importantes na Amazônia, constituindo-se em fonte de alimento, comércio, renda e lazer para grande

parte de sua população, especialmente a que reside nas margens dos rios de grande e médio porte. O próprio processo de colonização dessa região, desencadeado a partir dos séculos XVII e XVIII e centrado ao longo da calha do Solimões/Amazonas e de seus principais tributários é, em certa medida, o reflexo da importância dos rios e dos recursos pesqueiros na vida do homem amazônico. Mesmo em épocas mais remotas, há cerca de oito mil anos, quando a região era explorada apenas pelos índios, os peixes já se constituíam em recursos naturais importantes para a manutenção das populações humanas (Meggers, 1977; Roosevelt et al., 1991).

Apesar dessa longa trajetória no uso dos peixes, costuma-se delimitar o início da atividade pesqueira na Amazônia brasileira a partir do período colonial, com a criação dos pesqueiros reais, áreas de farta produção demarcadas pelas autoridades e nas quais os índios-pescadores eram obrigados a pescar para sustentar os militares, os religiosos e os funcionários da Fazenda Real (Veríssimo, 1895). Apenas a título de curiosidade, frente à cidade de Manaus existe uma vila denominada Careiro, ao lado da qual se localiza um lago ainda bastante piscoso, cujo nome é "Lago do Rei”, certamente uma alusão a tal fato.

Segundo Cerdeira et al. (1997) e Batista et al. (2004), as taxas de consumo de pescado na Amazônia são as maiores do mundo, com média estimada em 369 g/ pessoa/ dia ou $135 \mathrm{~kg} /$ ano, chegando a cerca de $600 \mathrm{~g} / \mathrm{dia}$ ou $22 \mathrm{~kg} / \mathrm{pes}$ soa / ano em certas áreas do baixo rio Solimões e alto Amazonas, constituindo-se na principal fonte de proteínas para as populações humanas residentes.

No período pré-colonial e durante os três primeiros séculos de colonização portuguesa, a pesca era exercida basicamente sobre o peixe-boi (Trichechus inunguis), a tartatura (Podocnemis expansa) e o pirarucu (Arapaima gigas), entretanto, dada a intensidade da pesca, esses animais tiveram suas populações drasticamente reduzidas, sendo que a das duas primeiras foi proibida há anos. Quanto ao pirarucu, trata-se de uma espécie ainda bastante visada pela pesca, aparecendo com freqüência nos principais mercados da região, apesar das normas de proibição de sua captura com base em seu tamanho mínimo, período reprodutivo e 
certas áreas de ocorrência. Ultimamente, no estado do Amazonas, a captura do pirarucu tem sido proibida o ano inteiro, embora tal medida não impeça que esse peixe seja constantemente encontrado em feiras e restaurantes.

Segundo Smith (1979) os principais aparelhos de pesca empregados pelos indígenas eram arco e flecha, embora anzóis rudimentares e redes confeccionadas com fibras vegetais já fossem usados por tribos que habitavam a região do Araguaia, no centro-oeste brasileiro.

Importante ruptura dos padrões tecnológicos da pesca amazônica ocorreu entre os anos de 1950 e 1970, com a introdução de aparelhos de alta capacidade de captura, feitos com fibras de nylon, uso de motores a diesel nas embarcações de pesca, aumento na fabricação de gelo e expansão da pesca comercial, incentivados por planos governamentais. Outro momento de extraordinária expansão se deu em meados da década de 1970, com o colapso das plantações de juta, ocasionado pela introdução de fibras sintéticas (Pereira, 2004).

Se do ponto de vista de inovações tecnológicas as mudanças têm sido lentas, o mesmo não se pode dizer do esforço aplicado e das taxas de demanda, os quais se têm dado de forma elevada e contínua, sobretudo nas últimas décadas. Além de atender a um mercado interno que se expande a taxas elevadas, a pesca amazônica também tem atendido ao mercado externo, tanto de outras regiões do país, como do estrangeiro.

A pesca é uma atividade destinada basicamente à alimentação e ao comércio e, por isso, enquadra-se numa das quatro categorias abaixo, conforme trabalhos de Barthem et al. (1997), Santos e Oliveira Jr. (1999) e Batista et al. (2004) e de acordo com critérios econômicos, geográficos e grau de profissionalização dos indivíduos nela envolvidos:

Pesca comercial: desenvolvida por pescadores profissionais e destinada à comercialização na própria região e, eventualmente, para outras regiões do país. Nela operam barcos regionais simples, com casco de madeira medindo de 4 a 16 $\mathrm{m}$ de comprimento. A pesca que vem sendo praticada nos reservatórios das grandes hidrelétricas da região, como Balbina, Samuel e Tucuruí, pode ser enquadrada nessa categoria.

Pesca industrial: desenvolvida por pescadores profissionais na região do estuário amazônico e destinada à exportação. Nela operam barcos possantes, com casco metálico de 17 a 29 m de comprimento. Neste caso, as capturas são feitas com redes em parelha. Trata-se de uma pesca bastante específica, centrada na Piramutaba (Brachyplatystoma vaillanti) e secundariamente nos pargos (Lutjanidae) e no camarão de água doce (Farfantepenaeus subtilis).

Pesca de peixes ornamentais: desenvolvida por pescadores artesanais de peixes vivos. A atividade é praticada com uso de canoas pequenas e puçás ou peneiras alongadas, próprias para uso entre a vegetação aquática. Os peixes vivos são transportados da área de coleta até Manaus em barcos, utilizando-se de bacias com água. Nessa cidade, são mantidos em viveiros até o momento da exporta- 
ção. Essa atividade está centralizada na bacia do rio Negro, sendo operada por seis a oito mil pescadores, denominados piabeiros (Prada-Pedreros, 1992). O comércio com o exterior é bancado por poucas mas tradicionais empresas do ramo e destinado especialmente aos mercados europeu, asiático e americano.

Pesca de subsistência: desenvolvida por pescadores ribeirinhos e destinada à sua alimentação e à de seus familiares. Quando bem-sucedida, parte da produção pode ser vendida a intermediários ou em feiras das vilas mais próximas. Trata-se de uma atividade difusa, praticada por milhares de pessoas e, por isso, sua produção é difícil de ser quantificada. É também muito expressiva do ponto de vista cultural, por ser uma atividade comumente praticada por gente de ambos os sexos e de todas as idades e categorias sociais.

Há que se considerar, além disso, a pesca esportiva, no sistema pesque-pague, pesque-solte e pesque-leve, que vem sendo desenvolvida sobretudo em rios e lagos de água mais clara, na periferia da planície amazônica, nos estados do Tocantins, Mato Grosso, Rondônia e Acre. Nessa categoria são empregados aparelhos simples, como molinete, anzol e linhada. Além de corpos d'água naturais, estações de piscicultura situadas próximas a cidades e vilas também têm servido a essa causa, concentrando grande número de praticantes, especialmente nos finais de semana e época de veraneio. Trata-se de uma atividade de grande valor lúdico e estético e que vem se firmando como importante alternativa turística na região.

Apesar da longa trajetória da pesca amazônica, durante séculos ela só foi divulgada pelo intermédio de viajantes e de registros históricos isolados, como os de Veríssimo (1895) e Meschkat (1961). Os primeiros bancos de dados e estudos sistematizados sobre ela só foram iniciados na década de 1970, com os trabalhos de Petrere (1978a e b) no estado do Amazonas; Goulding (1979 e 1980), em Rondônia e Smith (1979), no município de Itacoatiara (AM). A partir daí, uma série de trabalhos foram e continuam sendo realizados por pesquisadores do Instituto do Meio Ambiente dos Recursos Hídricos e da Amazônia Legal (Ibama), Instituto Nacional de Pesquisas da Amazônia (Inpa), Museu Paraense Emílio Goeldi e Universidades de Rio Claro (Unesp) e do Amazonas (Ufam). Em outras áreas amazônicas fora do território brasileiro, há que se destacar os trabalhos realizados pelo Instituto Nacional de Pesca y Acuicultura Amazónico, da Colômbia, e pelo Ministerio de Pesqueria, do Peru.

\section{Potencial pesqueiro}

Ainda não se conhece com exatidão o número de peixes que ocorrem na Amazônia, mas as estimativas mais citadas vão de 1,5 a seis mil espécies. Trabalhos mais recentes e específicos fixam esse número em cerca de três mil, embora dezenas de espécies novas sejam descritas a cada ano e outro tanto seja colocado em sinonímia. Apesar desse indeterminismo, há um consenso de que se trata da maior diversidade de peixes de água doce do mundo.

O número e a composição específica também variam entre rios com diferentes dimensões e tipos de água: o número médio por sub-bacias de médio a gran- 
de porte tem oscilado entre 250 a 450 espécies (Santos e Ferreira, 1999). Evidentemente, além da diversidade específica, pode haver também uma diversidade associada a grupos intrapopulacionais, o que potencializa ainda mais a diversidade geral dessa ictiofauna.

Uma característica da importante ictiofauna a ser destacada no contexto da pesca amazônica diz respeito às categorias taxonômicas e/ ou ecológicas nas quais os peixes são enquadrados. De maneira sumária, elas são as seguintes:

Characiformes ou peixes de escama: a maioria é formada de espécies migradoras de curta distância, movimentando-se entre rios e lagos. O principal representante dessa categoria é o Tambaqui (Colossoma macropomum), que alcança cerca de $1 \mathrm{~m}$ e $30 \mathrm{~kg}$ e até a década de 1980 era a espécie mais abundante na pesca. Os demais membros são de menor porte, entre 20 e $50 \mathrm{~cm}$ de comprimento, mas muito apreciados, destacando-se entre eles o jaraqui (Semaprochilodus spp), matrinxã (Brycon spp), curimatã (Prochilodus spp), pacu (Myleus spp, Mylossoma spp), sardinha (Triportheus spp) etc. Normalmente, esses peixes são vendidos em gelo, por quilo ou cambada, com várias unidades. Sua pesca é feita com rede de lanço ou arraste, aplicada sobre cardumes que estão se deslocando pelo canal para desovar (peixe ovado) ou à procura de novas áreas para alimentação e dispersão (peixe gordo).

Siluriformes, bagre ou peixe-liso: a maioria é formada por espécies que empreendem migrações longas, através do canal principal do sistema SolimõesAmazonas. Os principais representantes desse grupo são o sorubim (Pseudoplatystoma fasciatum), caparari (P. tigrinum), dourada (Brachyplatystoma rousseauxii), piramutaba (B. vaillantii) e piraíba (B. filamentosum), sendo esta o maior bagre de água doce, alcançando cerca de $2,4 \mathrm{~m}$ e $130 \mathrm{~kg}$. A pesca desses peixes é feita normalmente no canal ou em áreas de cachoeiras, com uso de redes de emalhe, espinhéis e linhada. Muitas pessoas, especialmente aquelas oriundas do interior, possuem certo tabu em relação ao consumo dos peixes lisos; por outro lado, trata-se de um tipo de pescado muito apreciado em outras regiões do Brasil e de países vizinhos, daí que grande parte da sua produção é exportada, especialmente para a Colômbia e Peru.

Perciformes, peixes sedentários, típicos de lagos e caracterizados por espinhos nas nadadeiras. Seus principais representantes são o tucunaré (Cichla spp) e a pescada de água doce (Plagioscion spp), ambos carnívoros e formados por várias espécies biológicas. Além da pesca comercial típica, o tucunaré é também bastante visado pela pesca esportiva, a qual vem se intensificando em certas áreas da Amazônia, especialmente nos rios de água clara e nos reservatórios de hidrelétricas. Na UHE Balbina, por exemplo, é realizado anualmente um campeonato de pesca dessa espécie, sendo essa uma das principais atrações turísticas do município de Presidente Figueiredo, onde tal reservatório está localizado.

Fato curioso dessa rica diversidade é que apenas cem a duzentas espécies são normalmente comercializadas, sob a designação de apenas trinta a cinqüenta 
nomes ou categorias populares distintas e com as quais as estatísticas pesqueiras normalmente trabalham. Isso significa que muitas espécies biológicas são tratadas sob um mesmo nome popular. Assim, se por um lado essa nomenclatura facilita a identificação do peixe pelo pescador e coletor de dados estatísticos, por outro dificulta o perfeito entendimento da dinâmica pesqueira, uma vez que as espécies biológicas, por mais parecidas que sejam, ocupam nichos especiais e se comportam de maneira distinta na natureza.

Além do número relativamente baixo de espécies utilizadas na pesca em relação ao grande potencial existente, observa-se também que a maior parte da produção pesqueira recai apenas sobre uma minoria delas. As dez principais espécies representam mais de $80 \%$ da produção dos mercados pesqueiros regionais. Com a pesca de peixe ornamental essa concentração é ainda maior, sendo o cardinal (Paracheirodon axelrodi) responsável por cerca de $80 \%$ dos peixes comercializados (Leite e Zuanon, 1991).

O preço do pescado também varia bastante em função do mercado, da espécie, da estação do ano e do tamanho do peixe, bem como de outros parâmetros. Entretanto, no mercado de Manaus, peixes importantes como o tambaqui valem quase o dobro da carne de gado e o triplo da carne de frango. Por outro lado, espécies pouco procuradas no comércio local décadas atrás, como os peixes lisos, são, hoje, bastante valorizadas, tanto para exportação como para consumo local. Parece haver uma tendência da participação do pescado constituído de espécies secundárias, à medida que as espécies principais vão se tornando menos abundantes e mais caras.

Além da inversão dos valores na produção pesqueira, nota-se, também, uma alteração no tamanho médio dos peixes mais procurados. Não raro, exemplares de tambaqui com 20 a $30 \mathrm{~cm}$ de comprimento são encontrados até mesmo em feiras administradas pelo município, quando o tamanho mínimo exigido para o comércio dessa espécie é de $55 \mathrm{~cm}$. Observa-se também que, ao contrário do que ocorria décadas atrás, quando esse peixe era vendido individualmente, hoje é comum encontrá-lo à venda em cambadas com cinco a dez exemplares, tal como ocorre com a sardinha, pacu e outros peixes considerados na pesca regional como miúdos.

É praticamente impossível determinar com certa precisão o potencial pesqueiro da bacia Amazônica, entretanto, cálculos efetuados por Bayley e Petrere Jr. (1989) e Merona (1993) dão conta de valores situados entre 270 mil e 902 mil toneladas/ ano, com base num rendimento médio de 40 a $60 \mathrm{~kg} / \mathrm{ha} / \mathrm{ano}$. Apesar das limitações de estimativas desse tipo, há um dado importante a considerar, que é justamente o fato de o potencial ser bem maior que a produção real atual, em torno de 200 mil toneladas / ano, segundo Bayley e Petrere (1989).

Tomando-se o preço médio do pescado, no início da cadeia de comercialização, a um valor médio de um dólar/ quilo, bem como o valor de 3,2 milhões oriundos do comércio de aproximadamente quinze milhões de peixes ornamen- 
tais, chega-se a mais de duzentos milhões de dólares/ ano no comércio pesqueiro amazônico. Bem mais significativo que esses valores financeiros, no entanto, é o número de pessoas que se dedicam à pesca como meio de subsistência, pois praticamente todas as famílias interioranas participam da atividade pesqueira. Assim, a pesca na Amazônia não é somente uma atividade comercial ou fonte de renda e alimentação, mas uma expressão cultural de suma importância, embora raramente seja abordada em trabalhos técnicos, de cunho eminentemente estatístico.

\section{Ambiente da pesca}

A hidrologia da bacia amazônica configura-se como um imenso complexo de rios, igarapés, lagos, canais e furos nos quais abriga cerca de $20 \%$ de toda água doce da terra. Segundo Melack (1984), na parte central da bacia, incluindo apenas o sistema Solimões/ Amazonas e seus principais tributários, ocorrem cera de 8,5 mil lagos, correspondendo a cerca de $11 \%$ dos 62 mil km² de planícies inundáveis, o que permite considerar esse universo aquoso de pátria das águas, nas palavras do poeta e escritor Thiago de Mello.

Em comum com a maioria das bacias hidrográficas de outras regiões de planície, o rio Amazonas é constituído por dois componentes básicos: o leito ou canal principal e as áreas marginais, inundáveis periodicamente. A oscilação do nível das águas faz com que, na época da cheia, esses dois componentes se confundam, tornando-se discerníveis apenas nas partes mais profundas, onde a correnteza é maior e a vegetação fixa não pode se estabelecer.

Do ponto de vista hidroquímico, a bacia é influenciada pelas montanhas andinas, de onde se originam os sedimentos ricos em minerais, responsáveis pela coloração barrenta, típica das águas brancas e pelos escudos das Guianas e Brasil Central, formadores de águas claras ou escuras, com baixo teor de sedimentos. Há que se destacar também as influências do oceano Atlântico, onde desembocam o rio Amazonas e o Tocantins. No total, a bacia cobre uma área superior de, aproximadamente, sete milhões de quilômetros quadrados, dos quais $58 \%$ localizam-se no Brasil e o restante nos países amazônicos vizinhos.

Embora nos rios de água clara e escura a diversidade da ictiofauna seja elevada e a pesca relativamente desenvolvida, a maior produção e produtividade biológica ocorrem nas águas brancas, para as quais também contribuem as áreas de várzea, colonizadas por extensos bancos de capins flutuantes e matas alagáveis, onde há abundância de hábitats utilizados pelos peixes. Apenas como exemplo ilustrativo dessa riqueza, cita-se o trabalho de Sánchez-Botero e Araújo-Lima (2001) que dá conta de 91 espécies de peixes, pertencentes a oito ordens, encontrados em bancos de macrófitas.

Um fator de grande importância nos rios da Amazônia central diz respeito aos pulsos de inundação, isto é, às grandes variações do nível das águas, entre 8 a $15 \mathrm{~m}$ entre os períodos de seca e cheia. Essas variações, embora decorrentes de um processo quase contínuo de subida e descida das águas, determinam quatro fases distintas, a saber: 
Enchente: fase mais duradoura, entre dezembro e abril, quando a maioria das espécies forma cardumes e empreende migrações para desovar na boca de igarapés ou nas margens dos rios, sendo seus ovos e larvas carreadas pela correnteza para as áreas que começam a ser inundadas.

Cheia: fase de duração curta, entre maio e junho. É nela que os peixes desovados e os jovens recrutas, em fase de crescimento, se alimentam intensamente, aproveitando a farta oferta de frutos, sementes, raízes, folhas e invertebrados e outros alimentos proporcionados pela floresta inundada. Essa intensa atividade alimentar resulta na produção e no acúmulo de gordura e outras substâncias de reserva, as quais serão utilizadas nas fases seguintes, tanto para suportar as condições adversas do meio como também para elaborar os produtos gonadais que serão utilizados na fase reprodutiva seguinte.

Vazante: fase intermediária de duração, entre julho a setembro. Corresponde ao período em que os peixes se agrupam para abandonar as áreas da floresta que começam a secar, iniciando a saída pelas ligações do lago com o rio e, a partir daí, pelo canal principal, em movimento de dispersão ascendente.

Seca: fase curta, entre outubro e novembro. É nessa ocasião que os peixes se tornam mais concentrados, por causa do menor volume de água. Essa época é crítica para a maioria deles, tanto por causa da maior vulnerabilidade à predação, como pela depleção de oxigênio nos corpos d'água mais rasos e sob forte influência de material em decomposição.

Considerando a grande dimensão e os diversos gradientes geográficos que fazem parte da bacia, resulta que essas fases ou estações se dão em momentos distintos ao longo de sua área de abrangência. Trata-se, portanto, de um fator adicional e importante para a complexidade da diversidade ictiofaunística, bem como do comportamento dos peixes e da dinâmica das pescarias.

\section{Exploração e manejo}

A exploração pesqueira na Amazônia é regida por várias Leis, Decretos, Portarias, Licenças e outras normas legais, destacando-se entre elas a Lei 7679/ 88 e o Decreto Federal 221/67, também denominado código da pesca, que é a base para a legislação pesqueira brasileira (Pereira, 2004).

Para efeito dessas normas, a pesca é considerada como toda atividade de captura de peixes ou quaisquer outros organismos animais ou vegetais que tenham na água o seu meio normal ou mais freqüente de vida e que seja ou não submetido a aproveitamento econômico. Como os corpos d'água e os organismos que neles vivem são de domínio público, o exercício da pesca é garantido a todas as pessoas devidamente registradas nas diversas categorias de pesca, dependendo de normas hierarquicamente inferiores e que tratam de temas regionalizados ou mais específicos.

Apesar da clareza e amplitude dessas normas, muitas vezes elas são desconhecidas ou incompreendidas. Mais grave ainda são os conflitos que ocasionalmente ocorrem por causa do choque de interesses no próprio âmbito da pesca 
ou desta com outras atividades paralelas ou concorrentes. Um dos principais conflitos registrados na Amazônia foi a "guerra do peixe" no lago Janauacá, nas proximidades de Manaus, em 1973, ainda que incidentes semelhantes tenham sido reportados em várias outras localidades amazônicas (Barthem et al., 1997).

Os conflitos da pesca, além de causar uma atmosfera de suspeita e insegurança generalizada, têm levado à destruição de barcos e equipamentos e mesmo à morte. Em geral, eles ocorrem entre pescadores nômades ou "de fora" e moradores locais, que consideram os lagos como propriedade sua ou da comunidade da qual faz parte. Os vários relatos e depoimentos apresentados no I Encontro de Pescadores artesanais do médio Amazonas Óbitos/ PA e no workshop política pesqueira para o estado do Pará: discussão e sugestões (Furtado, 1993), servem para explicitar tais situações conflituosas e constituem-se em um alerta importante para que as autoridades e a sociedade em geral tomem medidas preventivas para que o interior não venha assimilar a violência que já aflige as cidades de forma quase insuportável.

Independentemente de conflitos dessa natureza, o fato é que o manejo de recursos pesqueiros na Amazônia sempre foi e continua sendo extremamente difícil. As causas disso são variadas e inter-relacionadas, podendo-se destacar dentre elas a extensão e complexidade da bacia hidrográfica, a grande diversidade da ictiofauna e dos hábitos dos peixes, a grande variedade dos aparelhos e métodos de pesca, o enorme contingente de pescadores e seu deficiente sistema de organização profissional e de assistência por parte do poder público. Essas causas, por sua vez, constituem-se na principal razão da não aplicabilidade ou ineficácia de planos de manejo feitos para serem aplicados, indistintamente, nos diferentes sistemas aquáticos da bacia amazônica, como um todo.

Planos locais, baseados em métodos clássicos para o ordenamento e manejo dos estoques pesqueiros e água doce têm-se constituído em tentativas importantes para o controle da pesca, visando à pacificação de conflitos estabelecidos ou potenciais. Tais controles são estabelecidos normalmente por um ou mais critérios abaixo relacionados, tomando-se como base as classificações propostas por Welcomme (1983) e Batista et. al. (2004):

Área: proteção de áreas altamente sensíveis à pesca, como boca de lagos, encontro de rios, pé de cachoeiras e de barragens. Também é aplicada em forma de rodízio, em sistemas de lagos comunitários, com o objetivo de facilitar a reposição natural de estoques super-explorados e de áreas sob forte impacto humano, como nas proximidades das grandes cidades.

Apetrecho: aplicado tanto ao tipo e à dimensão dos aparelhos de pesca, como também ao tamanho de suas malhas e locais de uso. É uma forma de controle bastante usual na região, sendo também o objeto mais visado e fácil de ser apreendido, em caso de punição por infrações às leis de defeso.

Época: relacionado ao defeso da piracema, em época de reprodução. É aplicada normalmente a cada ano, por ocasião do período de desova, em geral no 
período de enchente, mas com ligeiras variações entre estados e regiões, já que as oscilações dos níveis dos rios variam temporal e espacialmente. Tem a vantagem de ser baseada num parâmetro biológico facilmente percebido e com forte poder de persuasão junto ao pescador e consumidor. Além disso, há o apoio governamental que faculta ao pescador profissional receber uma certa quantia em dinheiro como medida compensadora pela suspensão obrigatória da atividade pesqueira.

Quantidade: estipulação de cotas ou licenças em conformidade com o número de pescadores e de barcos que operam numa determinada área ou época de pesca, denominada safra. É um tipo de controle pouco usual na Amazônia, embora tenha sido experimentado em estoques específicos, como foi o caso da piramutaba no estuário e do tucunaré, no reservatório da UHE Balbina.

Espécies-alvo: controle misto, que leva em consideração não somente a espécie biológica em si, mas suas características relativas a tamanho mínimo de primeira maturação, época de desova etc. Esta tática é normalmente utilizada para espécies ameaçadas, de alto valor comercial ou bem estudadas cientificamente. Tem a vantagem de se trabalhar com parâmetros biológicos bem definidos, entretanto, os entraves administrativos e as pressões de demanda acabam dificultando sua operacionalidade.

Tamanho da frota: similar à da limitação por cota de captura, só que, em vez de levar em consideração as espécies-alvo, é aplicada sobre o número de unidades credenciadas na atividade pesqueira de uma determinada região. Exceto recursos pesqueiros específicos, como o caso da Piramutaba no estuário e de algumas experiências em reservatórios de hidrelétricas, é uma tática pouco utilizada no restante da Amazônia.

Acordos comunitários: consensos ou acertos informais entre pescadores e comunitários, com vista ao uso comum ou gestão compartilhada de determinados lagos. Trata-se de modelos alternativos relativamente novos, centrados em discussões a ações coletivas e que vêm sendo orientadores de novas políticas públicas para o setor. Exemplos bem-sucedidos de iniciativas desse tipo são representados pelos projetos Mamirauá (Museu Goeldi e governo do Amazonas), na região de Tefé; Iara (Ibama-GTZ), na região de Santarém e Pyrá (Ufam), em alguns lagos próximos a Manaus (Ribeiro e Fabré, 2003).

\section{Desafios e perspectivas}

A Amazônia detém a maior biodiversidade e é um dos ecossistemas mais íntegros e produtivos do planeta. Apesar disso, ou talvez por isso mesmo, é a região que mais tem chamado a atenção do mundo e enfrentado os maiores desafios para se desenvolver de forma harmônica e sustentável.

Os problemas enfrentados pelo setor pesqueiro são variados, às vezes interdependentes, entretanto, em linhas gerais, os mais importantes dizem respeito à própria atividade pesqueira e, secundariamente, à aqüicultura e à tecnologia do pescado. 
No caso da pesca, praticamente toda a produção dos barcos pesqueiros é acondicionada, transportada e vendida em gelo. Como não há infra-estrutura suficiente para isso, ocorre normalmente que os peixes de segunda categoria capturados acabam sendo desbaratados ou mesmo lançados fora para ceder lugar às espécies mais importantes capturadas simultaneamente ou num momento posterior. Estimativas informais dão conta de até $30 \%$ de estrago do pescado, por atitudes desse tipo.

Alguns fundamentos científicos e a própria percepção cultural do pescador são suficientes para indicar o período de desova como o momento mais apropriado para aplicação das leis de defeso. Afinal, o período de desova corresponde ao ápice da vida dos reprodutores, quando eles estão gerando novos seres semelhantes a si mesmos e quando seu estado fisiológico inspira cuidados. Entretanto, há que se considerar que o período de desova corresponde à enchente dos rios, havendo melhores condições de escape que o período da seca, quando os peixes normalmente ficam isolados. Nesse período, tanto as taxas de predação natural como de vulnerabilidade à pesca se tornam enormes, talvez ainda maiores que no período da reprodução. É também no período de seca que o esforço de pesca se acentua e as perdas aumentam, já que o mercado está saturado e mais exigente quanto à qualidade do pescado. Importa considerar que a perda dos indivíduos aptos a reproduzir acaba resultando em prejuízo para a população, quer eles sejam sacrificados na seca, quando ainda em repouso ou logo depois, na enchente, quando estão reproduzindo. Assim sendo, as leis de defeso tradicionalmente aplicadas na época de reprodução também deveriam ser aplicadas no período de seca, pelas razões expostas.

Questionamentos e sugestões semelhantes a esses já foram apresentados por Isaac et al. (1993) em relação às restrições da pesca na região do médio Amazonas. Essa convergência de idéias pode ser um processo estruturante de novos parâmetros ou, talvez, de implementação de modelos alternativos capazes de contribuir para o aprimoramento da gestão dos recursos pesqueiros da região.

Outra questão relevante no universo da pesca amazônica diz respeito aos conflitos que vêm pautando as relação dos pescadores profissionais, considerados "gente de fora" com os ribeirinhos, tanto pescadores artesanais, como agricultores e criadores de gado.

Barthem et al. (1997), Ribeiro e Fabré (2003), Batista et al. (2004) Issac e Cerdeira (2004) analisam de maneira detalhada essa situação, ao mesmo tempo em que advogam a ação de órgãos governamentais, como o Ibama e de organizações não governamentais para apoiar as lideranças locais na resolução dos problemas enfrentados com a gestão compartilhada dos recursos. Embora as intenções sejam boas e o caminho certo seja esse, há que se considerar que os acordos de pesca ainda se encontram em fase de experimentação, têm ação localizada e, em alguns casos, suscitam dúvidas quanto à sua legalidade formal, não sendo, portanto, um mecanismo capaz de fazer frente a uma situação mais generalizada e que requer solução de longo prazo. 
A diminuição de alguns estoques pesqueiros da região já é fato bastante conhecido, tanto pela redução da quantidade como do tamanho de algumas espécies. O pirarucu e o tambaqui são claros exemplos disso. Crampton (1999) chama a atenção para o fato de que um grande número de espécies raras ou mesmo endêmicas possa estar sendo explorado na pesca de peixes ornamentais, em níveis acima da capacidade de suporte e, portanto, com sérias ameaças aos estoques naturais.

À parte das implicações político-administrativas, limitações técnicas quanto à infra-estrutura e deficiências no manejo, o setor pesqueiro também é vítima das lacunas de conhecimentos técnico-científicos. Quanto a isso, cabe mencionar a falta de séries históricas dos níveis de produção pesqueira em grande parte dos mercados e as questões ainda não esclarecidas quanto à correta identificação e hábitos de vida de muitas espécies de peixes. Paralelamente a isso, há também que mencionar a deficiência de infra-estrutura laboratorial e de pesquisadores e técnicos em número e qualidade suficientes para a geração dos conhecimentos necessários para atendimento das demandas reais e reprimidas do setor, incluindo pesquisa, ensino e extensão.

A piscicultura vem sendo testada na Amazônia de diferentes maneiras, incluindo tanques artificiais, represamento de nascentes, fechamento de trechos de igarapés, gaiolas flutuantes e até repovoamento de lagos e lagoas, embora ainda existam obstáculos que precisam ser superados para que ela se desenvolva plenamente e possa enfrentar a concorrência do pescado natural, quase sempre mais apreciado e acessível a menor preço nos mercados locais.

Evidentemente, por se tratar de atividade que não tem tradição na região, que requer infra-estrutura física e técnica e envolve custos operacionais, padece de sérias limitações. Dentre essas, podem ser destacadas a falta de "pacotes tecnológicos" aplicáveis às condições amazônicas, a escassez ou inconstância de matérias-primas para fabricação de razão, altas taxas de predação, incluindo o furto, além da suscetibilidade de fuga pelo rompimento das barragens na ocasião das chuvas e morte causada pela desoxigenação das águas, devido às altas temperaturas e proliferação de microorganismos concorrentes. Apesar disso, esforço crescente e resultados promissores estão à prova, evidenciando que essa atividade é bastante estratégica para a região, sobretudo por causa de fatores positivos disponíveis, como abundância de água, condições climáticas e aumento de demandas.

Quanto à tecnologia do pescado, trabalhos pioneiros vêm sendo desenvolvidos há cerca de duas décadas por pesquisadores do Instituto Nacional de Pesquisas da Amazônia com o apoio de órgãos regionais de apoio e fomento. Resultados promissores vêm sendo obtidos de técnicas modernas e mais eficientes de salga, secagem e congelamento, bem como na agregação de valor, transformando o pescado em fishburger, defumados, triturados, empanados, marinados, surimi (Jesus et al., 1991). Tratamento tecnológico tem sido aplicado também na transformação da pele de peixes em couro para fabricação de vestimentas, sapatos, 
cintos, bolsas e carteiras, dentre outros. Tais produtos e processos ainda se encontram em fase experimental, sendo que seus contornos tecnológicos e de mercado ainda não estão bem delineados. É provável que os principais obstáculos atuais estejam relacionados à falta de infra-estrutura e equipamentos indispensáveis para uma produção em larga escala, abertura de mercado e garantia de lucratividade.

Além das dificuldades inerentes a esses dois setores específicos, a pesca amazônica, em seu sentido amplo, enfrenta outros problemas relativos à insuficiência de recursos humanos e financeiros e, talvez mais importante, à falta de conscientização dos atores da pesca e da sociedade em geral sobre a real importância da preservação e uso responsável dos recursos pesqueiros e do meio ambiente como um todo.

No entanto, deve-se considerar que, ao lado das dificuldades e limitações, há também aspectos positivos, como a extraordinária diversidade biológica e potencialidade de recursos naturais, experiências pioneiras bem-sucedidas em áreas estratégicas e um apelo natural que o nome da Amazônia desperta em todo o mundo, indicando boa acolhida e sucesso em todos os produtos, serviços e processos de qualidade oriundos dessa região.

Se, por um lado, a Amazônia insere-se cada vez mais nos circuitos econômicos globalizados, por outro, suas causas e interesses não raro se chocam com os de outras regiões, levando a impasses complicados.

Embora o dilema do desenvolvimento amazônico seja formado por componentes de diversos matizes, observa-se que ele se insere em duas vertentes políticas e socioeconômicas bem definidas e que se afiguram como complementares, ou mesmo como antagônicas: de um lado, a vertente produtivista ou economicista, orientada pelo mercado globalizado e produção em escala e onde a ocupação territorial se faz tanto pelos tratores e colheitadeiras modernas, como pela motosserra ou mesmo pelo machado. De outro lado, predomina a vertente ecológica ou preservacionista, orientada pela idéia de vazio demográfico, reservas intocáveis e onde a floresta'é vista mais como santuário que recurso a ser explorado.

Talvez por não ser um elemento biológico fixo - como a floresta - e não se enquadrar no modelo clássico de territorialidade, o setor pesqueiro parecer ficar à mercê, ou melhor, bloqueado por essas duas vertentes, sem autonomia ou política própria. Nessa situação, é visto ora como um celeiro, potencial inesgotável e acessível a todos o tempo todo, ora não passa de recursos transitórios, sem dono.

Dubiedades e indefinições dessa natureza parecem ter levado o setor pesqueiro a um estado de letargia crônica e onde planejamentos, mesmo amplamente discutidos, demoram ou jamais são implementados. Exemplos típicos dessa situação são o terminal pesqueiro de Manaus, projetado há mais de trinta anos e a infra-estrutura da frota e dos mercados pesqueiros da região, quase sempre obsoleta, sem segurança e higiene.

No caso de Manaus, onde opera uma zona franca farta em subsídios e geradora de vultosos recursos, essa situação chega a ser chocante, porque contrasta totalmente com o nível de adequação e sofisticação tecnológica emprega- 
do pela maioria das empresas ali sediadas. Paradoxalmente, enquanto o setor pesqueiro se utiliza dos recursos naturais abundantes na região, a maioria de tais empresas trabalha com componentes eletrônicos ou matérias-primas oriundas de regiões longínquas.

As características ambientais e climáticas, especialmente os ciclos de chuva e de inundação dos rios, determinam ou influenciam o padrão de distribuição e a ecologia geral dos peixes e, conseqüentemente, o padrão da pesca e do comportamento do pescador. Como elementos do final da cadeia produtiva, até mesmo a indústria, o comércio e o próprio consumidor acabam sendo afetados e, em certa medida, também afetam tais condições. Essa premissa é importante não somente para as considerações ecológicas que devem ser feitas quando se busca um entendimento amplo das variáveis ambientais e suas inter-relações, mas sobretudo para uma definição de conceitos gerais e adoção de medidas eficazes no manejo dos recursos pesqueiros. Nesse sentido, todo e qualquer plano de manejo que seja alicerçado na exata noção de sustentabilidade deve sempre levar em consideração os dois princípios seguintes:

- A bacia hidrográfica amazônica funciona como um sistema amplo, aberto e integrado, sendo determinante para isso os fluxos de energia entre o ambiente aquático e o terrestre, especialmente as áreas de mata alagada e as macrófitas aquáticas. Além de fontes alimentares diretas, essas plantas contribuem com o fornecimento de alimentos secundários, abrigo, esconderijo e espaços vitais.

- Os níveis de produção de pescado, o comportamento dos peixes e a atividade pesqueira estão intrinsecamente relacionados com os pulsos de inundação; assim sendo, as leis de defeso devem levar em consideração não apenas o período de desova, como vem sendo feito historicamente, mas a vulnerabilidade dos estoques à captura no pico da seca, quando os peixes se encontram naturalmente isolados e sem condições de defesa.

\section{Sustentabilidade}

O ponto principal a considerar quando se evoca a sustentabilidade do setor pesqueiro é que a redução dos estoques pesqueiros e demais efeitos negativos que se abatem sobre a ictiofauna não advêm exclusivamente da pesca, mas de impactos negativos do entorno, como a derrubada das matas ciliares, a destruição de nascentes, o assoreamento, a poluição e o represamento de rios. Assim sendo, atividades potencialmente impactantes e em processo de desenvolvimento na Amazônia, como a cultura de soja, a mineração, a construção de barragens e estradas devem ser enfaticamente levadas em consideração quando se trata de política ambiental voltada para a preservação e sustentabilidade dos recursos naturais.

Em suas preleções sobre a limnologia amazônica, o Dr. Herald Sioli costumava afirmar que as águas dos rios são a urina da paisagem. Ou seja, que as condições do ambiente aquático são reflexos do que ocorre no ambiente terrestre circundante. 
A bacia sedimentar amazônica possui cerca de dois milhões de quilômetros quadrados e é formada por terrenos planos e pouco consolidados, com declividade baixa, em torno de $2 \mathrm{~cm}$ por quilômetro e fraca correnteza. Tal situação favorece a formação de uma complexa rede de rios e furos meândricos, levando também a um processo dinâmico de construção e desconstrução de suas margens. Essa configuração é muito importante e deve ser levada em consideração com respeito ao manejo das atividades planejadas ou em curso na Amazônia, pois os processos desencadeados nas áreas periféricas acabarão inevitavelmente se repercutindo no interior da bacia. No caso do Brasil, isso é particularmente grave, porque, além de conter a foz do Amazonas e de seus principais afluentes, é nas vertentes do seu escudo central que as operações mineradoras estão atuando há anos, deixando como rastro crateras e altas concentrações de mercúrio, utilizado na extração de ouro. É também nessa região onde se concentra o desmatamento para retirada de madeira e formação de pastagens, com intensas queimadas, levando ao que se convencionou denominar "arco do fogo" e que atualmente se estabelece a principal fronteira agrícola, representada pela plantação da soja. Trata-se de um processo vertiginoso que teve origem nas regiões sul-sudeste, passando em seguida pelo centro-oeste e agora invadindo a Amazônia em várias frentes.

A bacia amazônica forma uma unidade de drenagem estruturalmente bem definida, mas encontra-se sob jurisdição de nove países. Mesmo admitindo que cada um deles pode e deve implementar suas próprias políticas, de acordo com suas particularidades e interesses, é evidente que deve haver uma pauta mínima para ações comuns, capazes de otimizar o uso e viabilizar a proteção dos recursos naturais transfronteiriços. Isso é particularmente válido para os peixes migradores de longa distância, como os grandes siluriformes que normalmente se deslocam entre o estuário e as nascentes do Amazonas e seus principais afluentes de água branca.

Torna-se evidente que os planos de manejo devem abranger toda sua área de distribuição e não apenas espaços delimitados politicamente. Assim sendo, acordos multinacionais já bem estabelecidos, como Tratado de Cooperação Amazônica (TCA), e a Comissão para a Pesca Interior na América Latina (Cpescal) poderiam constituir-se em instâncias apropriadas para a implementação de tais ações, sobretudo nas áreas de pesquisa científica e estratégias protecionistas de estoques e áreas de endemismo

Em condições naturais, a ictiofauna e o ambiente aquático formam uma unidade coesa, harmônica e equilibrada; assim, planos de manejo alicerçados em elementares princípios de sustentabilidade devem focar não apenas a atividade pesqueira, mas as condições humanas do entorno, a qualidade da água e das áreas de terra firme drenadas por ela. Evidentemente, esse entendimento não é uma novidade. Aliás, os princípios gerais contidos no código de conduta para a pesca responsável, editado pela FAO em 1995, apontam exatamente nessa direção ao afirmar que "os estados e os usuários dos recursos aquáticos deveriam conservar os ecossistemas dos quais eles dependem. O direito de pescar traz 
consigo a obrigação de fazê-lo de forma responsável, a fim de assegurar a conservação e a gestão efetiva dos recursos aquáticos vivos". O mais importante, no entanto, é que tais princípios sejam transformados em ação o quanto antes, de forma efetiva e duradoura.

Ainda a respeito da necessidade de inserção da pesca numa estratégia mais ampla de desenvolvimento, o referido código de conduta é bem explícito, ao afirmar:

a ordenação da pesca deveria fomentar a manutenção da qualidade, a diversidade e a disponibilidade dos recursos pesqueiros em quantidade suficiente para as gerações presentes e futuras, no contexto da segurança alimentar, o alívio da pobreza e o desenvolvimento sustentável. As medidas de ordenação deveriam assegurar a conservação não somente das espécies objeto da pesca, mas também daquelas outras pertencentes ao mesmo ecossistema, dependentes ou associadas a elas.

A despeito dos conflitos de interesse e dos embates presentes ou futuros, parece haver um consenso de que a manutenção da integridade do ecossistema amazônico é fundamental para todo e qualquer tipo de iniciativas que visem à sua exploração e desenvolvimento em bases sustentáveis. Nesse contexto, independentemente de políticas, métodos, estratégias, táticas ou técnicas evocadas ou levadas a termo, a educação ambiental é o fundamento dessa sustentabilidade. A educação ambiental é o foco especial desse contexto porque, além de constituirse num instrumento capaz de garantir a eficácia da pesca e promover a utilização dos recursos pesqueiros de forma sustentável, ela também é um fim em si mesma, responsável pela auto-afirmação da região, senso de cidadania de seu povo e de realização plena das pessoas que aí vivem e trabalham.

Fica claro, portanto, que a conservação dos recursos pesqueiros não deve ser uma atribuição apenas dos que participam diretamente da pesca, mas também de pecuaristas, industriais, fazendeiros, sitiantes, consumidores, poder público e sociedade em geral. Isso significa que a gestão dos recursos pesqueiros deve estar inserida na gestão ambiental ampla e ser feita de forma compartilhada entre todos os agentes sociais.

Para isso, é de fundamental importância e urgência a educação ambiental, a qual deve constituir-se não apenas em instrumento de impregnação de saberes e valores, mas, sobretudo, como forma de correção e aperfeiçoamento dos valores reinantes na sociedade capitalista em que vivemos, dominada pela cultura do egoísmo e do lucro fácil, a qualquer custo.

Embora ainda pouco divulgado, existe no Brasil um programa nacional de educação ambiental. Evidentemente, tal programa deve abrigar os aspectos culturais, técnicos e econômicos da pesca, fazendo deles um elemento de ampliação dos saberes, bem como uma instância aberta e participativa para a busca de soluções de problemas comuns, para o aproveitamento integrado das potencialidades e melhoria da qualidade de vida do homem e do meio em que vive. 
Estudos, pesquisas, acordos e leis restritas à área da pesca e dos recursos pesqueiros são importantes no processo de avanço do conhecimento, apaziguamento de conflitos e integração do homem no espaço amazônico, mas sem a educação que leva à conscientização e mudança de comportamentos, tudo isso não passa de paliativos ou soluções efêmeras.

Os moldes da educação ambiental aqui apregoada não se referem apenas às boas técnicas de manejo, à visão mercadológica que a genuína natureza amazônica representa para o mundo capitalista globalizado ou o simples ato de preservar por preservar, mas à clara consciência da relação histórico-evolutiva que natureza e homem têm em comum e da missão bíblica que a este compete, de dominar a terra, a água e os bichos que nelas vivem. Domínio este que deve estabelecer-se, não apenas pelas normas técnicas e conhecimentos científicos, sempre muito lembrados, mas especialmente pelo profundo senso de amorização e responsabilidade ética, quase sempre esquecidos.

\section{Referências}

BARTHEM, R. B., PETRERE JR., M.; ISSAC, V.; RIBEIRO, M. C. L. D. B., MCGRATH, D. G., VIEIRA, I. J e BARCO, M. V. "A pesca na Amazônia: problemas e perspectivas para o seu manejo". Em VALLADARES-PÁDUA, C. e BODMER, R. E. (eds.). Manejo e conservação de vida silvestre no Brasil. Rio de Janeiro, MCT/ CNPq/Sociedade Civil Mamirauá, 1997, pp 173-185.

BATISTA, V. S.; ISSAC,V. J. e VIANA, J. P. “Exploração e manejo dos recursos pesqueiros da Amazônia". Em RUFINO, M. L. (ed.). A pesca e os recursos pesqueiros na Amazônia brasileira. ProVárzea. Manaus, Ibama, 2004, pp. 63-152, 268 p.

BAYLEY, P. B. "Fish Yield from the Amazon in Brazil: Comparisons with African River Yields and Management Possibilities". Trans. Am. Fish. Soc., vol. 110, 1981, pp. 351359.

BAYLEY, P. B. e PETRERE Jr., M. “Amazon Fisheries: Assessment Methods, Current Status and Management Options". Can. Publ. Fisheries and Aquat. Scien., vol. 106, 1989, pp. 385-398.

CERDEIRA, R. G. P.; RUFFINO, M. L. e ISAAC, V. J. "Consumo de pescado e outros alimentos pela população ribeirinha do lago grande de Monte Alegre, PA. Brasil". Acta Amazonica, 27 (3), 1997, pp. 213-228.

CRAMPTON, W. G. R. "Plano de manejo preliminar para o uso sustentável de peixes ornamentais na Reserva Mamirauá". Em QUEIROZ, H. L. e CRAMPTON, W. G. R. (eds.). Estratégias de manejo para recursos pesqueiros na Reserva de Desenvolvimento Sustentável Mamirauá. Brasília, MCT-CNPq/ Sociedade Civil Mamirauá, 1999, pp. 159-176.

FURTADO, L. G. "Reservas pesqueiras, uma alternativa de subsistência e de preservação ambiental: reflexões a partir de uma proposta de pescadores do Médio Amazonas”. Em FURTADO, L., MELLO, F. e LEITÃO, W. (eds.). Povos das águas: realidade e perspectiva na Amazônia. MPEG/UFPA, Belém, 1993, pp. 243-276, 292 p.

GOULDING, M. Ecologia da pesca no rio Madeira. Manaus, Inpa, 1979, 172 p. 
. The Fish and the Forest. Los Angeles, University of California Press, 1980, $200 \mathrm{p}$.

HARTMANN, W. D. "Conflitos de pesca em águas interiores da Amazónia e tentativas para sua solução”. Encontro de Ciências Sociais e o Mar. 3. São Paulo, 3-5 abr. 1989, pp. 1-14.

HENDERSON, P. e CRAMPTON, W. G. R. "A Compararison of Fish Diversity and Abundance between Nutrient-Rich and Nutrient-Poor Lakes in the Upper Amazon". Journal of Tropical Ecology, n. 13, 1997, pp. 173-198.

ISAAC, V. J.; ROCHA, V. L. C. e MOTA, S. "Considerações sobre a legislação da 'piracema' e outras restrições da pesca na região do médio Amazonas". Em FURTADO, L.; LEITÃO, W. e MELLO, F. (eds.). Povos das Águas - realidade e perspectivas na Amazônia. Belém, MCT/CNPq/ MPEG, 1993, pp. 188-211, 292 p.

ISAAC, V. J. e CERDEIRA, R. G. P. Avaliação e monitoramento de impacto dos acordos de pesca. ProVárzea. Manaus, Ibama, 2004, 61 p.

JESUS, R. S; FALCÃO, P. T; CARVALHO, N. L. A e CARNEIRO, R. X. "Técnicas para a conservação e industrialização de pescado na Amazônia”. Em VAL, L.; FIGLIUOLO, R. e FELDBERG, E. Bases Científicas para estratégias de preservação e desenvolvimento da Amazônia: fatos e perspectivas, vol. 1. Manaus, Inpa, 1991, pp 417-440.

LEITE, R. G. e ZUANON, J. "Peixes ornamentais - aspectos de comercialização, ecologia, legislação e propostas para um melhor aproveitamento". Em VAL, L.; FIGLIUOLO, R. e FELDBERG, E. Bases científicas para estratégias de preservação e desenvolvimento da Amazônia: fatos e perspectivas, vol. 1. Manaus, Inpa, 1991, pp. 327-331.

MEGGERS, B. Amazônia: a ilusão de um paraíso. Rio de Janeiro, Civilização Brasileira, 1977, $207 \mathrm{p}$.

MELACK, J. M. “Amazon Floodpalins Lakes: Shape, Fetch and Stratificaton”. Verh. Internat. Verein. Limnol., n. 22, 1984, pp. 1278-1282.

MERONA, B de. "Pesca e ecologia dos recursos aquáticos na Amazônia". Em FURTADO, L., LEITÃO, W. e MELO, F. (ed.). Povos das águas - realidade e perspectiva na Amazônia. Belém, MPEG/ UFPA, 1993, pp. 159-185, 292 p.

MESCHAT, A. "Reports to the Government of Brazil on the Fisheries of the Amazon Region”. FAO Report 1305, Roma, BR/ TE/ Fi, 1961, 76 p.

PEREIRA, H. S. Iniciativas de co-gestão dos recursos naturais da várzea. Documentos técnicos. ProVárzea. Manaus, Ibama, 2004, 128p.

PETRERE JR., M. "Pesca e esforço de pesca no estado do Amazonas. I. Esforço e captura por unidade de esforço". Acta Amazonica, n. 8, 1978a, pp. 439-454.

"Pesca e esforço de pesca no estado do Amazonas. II. Locais e aparelhos de captura e estatística de desembarque". Acta Amazonica (suplemento 2), 1978b, pp. $1-54$.

PRADA-PEDREROS, S. Abundância e distribuição do cardinal, Paracheirodon axelrodi (Pisces, Characidae) e diversidade dos peixes nas planícies inundáveis de tributários do médio rio Negro, Brasil. Dissertação de Mestrado. Manaus, Inpa-Ufam, 1992, 74 p.

RIBEIRO, M. e FABRÉ, N. N. Sistemas abertos sustentáveis - SAS. Uma alternativa de gestão ambiental na Amazônia. Manaus, Edua, 2003, 243 p.

ROOSEVELT, C.; HOUSLEY, R. A; IMAZIO DA SILVEIRA, M.; MARANCA, S. e 
JOHNSON, R. "Eighth Millenium Pottery from a Prehistoric Shell Medden in the Brazilian Amazon”. Science, n. 254, 1991, pp. 1621-1624.

SÁNCHES-BOTERO, J. I. e ARAÚJO-LIMA, C. R. M. “As macrófitas aquáticas como berçário para a ictiofauna da várzea do rio Amazonas”. Acta amazonica, 31 (3), 2001, pp. 437-447.

SANTOS, G. M. e FERREIRA, E. J. G. "Peixes da bacia amazônica”. Em LOWEMCCONNELL, R. Estudos ecológicos de comunidades de peixes tropicais. São Paulo, Edusp, 1999, pp. 345-373, 534 p.

SANTOS, G. M. e OLIVEIRA JR. B. "A pesca no reservatório da Hidrelétrica de Balbina (Amazonas, Brasil)”. Acta Amazonica, 29 (1), 1999, pp. 145-163.

SIOLI, H. "Studies in Amazonian Waters". Atas do simpósio sobre a biota amazônica, n. 3, 1967, pp. 9-50.

SMITH, N. J. H. Pesca no rio Amazonas. Manaus, Inpa/ CNPq, 1979, 154 p.

VERÍSSIMO, J. A pesca na Amazônia. Rio de Janeiro, Livraria Alves, 1895, 137 p.

WELCOMME, R. “River basins”. FAO Fish. Tech. Pap., n. 202, 1983, pp. 1-60.

RESUMO - NO PRESENTE trabalho é feita uma síntese dos conhecimentos sobre a atividade pesqueira na Amazônia, incluindo histórico, potencial e tipos de pesca, composição do pescado e principais entraves e estratégias de manejo adotadas. Discute-se a inter-relação da pesca com as condições do ambiente aquático e a importância da vegetação ripariana ou mata ciliar como fonte de alimento, abrigo e refúgio para os peixes. Defende-se a idéia de que o manejo dos recursos pesqueiros só será bem-sucedido e eficaz se for compartilhado por todos os atores sociais direta e indiretamente envolvidos na pesca, e não apenas os pescadores, consumidores e comerciantes de peixes. O trabalho aponta a educação ambiental como a estratégia mais importante e talvez único caminho para a real sustentabilidade da pesca e, por conseguinte, dos recursos pesqueiros amazônicos. Palavras-chave: Pesca; Amazônia; várzea; sustentabilidade; recursos pesqueiros.

AbstraCt - IN THIS PAPER we present a synthesis of the knowledge on aquatic environments and commercial fishing in the Brazilian Amazon as well as the history, potential and types of fishing, the composition of exploited species, problems and the main management tactics adopted. The interrelationship of fishing with environmental conditions is discussed as well as the importance of marginal vegetation as a source of food, shelter and refuge for fish. We put forth the idea that the management of fish resources will only be effective if it is practiced by all social actors involved and not only the fishermen and consumers. Environmental education is pointed out to be the most efficient strategy for fishing policies and the only real way towards a real sustentability of the fishing and consequently the natural resources of the region.

Key-words: Fishing; Amazon; floodplain; sustainability; fishing stock.

Geraldo Mendes dos Santos é pesquisador titular do Instituto Nacional de Pesquisas da Amazônia (Inpa) e coordenador de pesquisas em biologia aquática. @-gsantos@inpa.gov.br Ana Carolina Mendes dos Santos é mestranda em política e gestão ambiental do Centro de Desenvolvimento Sustentável da Universidade de Brasília (UnB).

Texto recebido em 23/2/2005 e aceito em 18/4/2005. 